\title{
Effects of Gomisin A on Hepatocarcinogenesis by 3'-Methyl-4-dimethylaminoazobenzene in Rats
}

\author{
Ken-ichi Miyamoto, Shinya Wakusawa, Masaaki Nomura, Fujiko Sanae,

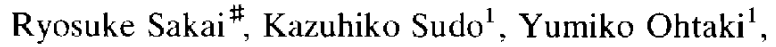 \\ Shigefumi Takeda ${ }^{1}$ and Yuichi Fujii ${ }^{1}$ \\ Research Laboratory for Development of Medicine, Hokuriku University School of Pharmacy, \\ Kanazawa 920-11, Japan \\ ${ }^{1}$ Tsumura Research Institute for Pharmacology, Ibaraki 300-11, Japan
}

Received April 3, $1991 \quad$ Accepted June 7, 1991

\begin{abstract}
We examined the effects of gomisin A on tumor promotion in the liver after a short-term feeding of 3'-methyl-4-dimethylaminoazobenzene (3'-MeDAB) to rats, compared with the effects of phenobarbital. Male Donryu rats were fed ad libitum a diet containing $0.06 \% 33^{\prime}-\mathrm{MeDAB}$ and $0.03 \%$ or $0.01 \%$ gomisin $\mathrm{A}$ or water containing $0.05 \%$ phenobarbital. Gomisin A and phenobarbital did not cause any proliferative and neoplastic lesions by themselves in 40 weeks of feeding. Altered foci in the liver increased with a peak at 12 weeks after the rats were fed 3'-MeDAB. Gomi$\sin A$ decreased the number of hepatic altered foci such as the clear cell and basophilic cell type foci in the early stages. Phenobarbital enhanced neoplastic alterations so that the number and size of the foci were much larger in the phenobarbital-combined group than in the 3'-MeDAB-control group. Thus, phenobarbital acted as a promoter of cells initiated by 3'-MeDAB; on the other hand, gomisin A showed a weak suppressive effect on tumor promotion.
\end{abstract}

We have reported that gomisin A, a lignan component isolated from Schizandra fruits (1), inhibits liver injuries induced by several hepatotoxic chemicals $(2-5)$ and enhances regeneration of the liver after a partial hepatectomy $(6-8)$. These effects of gomisin $\mathrm{A}$ are based on its ability to promote the recovery of liver functions, protect hepatocytes, inhibit cytotoxic cells in the liver, and increase hepatic blood flow, etc. On the other hand, phenobarbital, which induces liver metabolizing enzymes and accelerates liver cell proliferation, enhances hepatocarcinogenesis when given after a

\#Present address: Hokuriku Gakuin Junior College, Mitsukoji, Kanazawa 920, Japan short-term treatment with hepatocarcinogens $(9-11)$.

Because of the above-described properties of gomisin A, we determined its effects on hepatocarcinogenesis. In this study, we histopathologically examined the effects of gomisin A on the progression of carcinogenesis in the liver after a short-term treatment with 3'MeDAB, which selectively causes parenchymal cell carcinoma in the liver of rats (12).

\section{MATERIALS AND METHODS}

\section{Materials}

Gomisin A (Fig. 1) was isolated from Schizandra fruits (1). The basal diet (CE-2) 


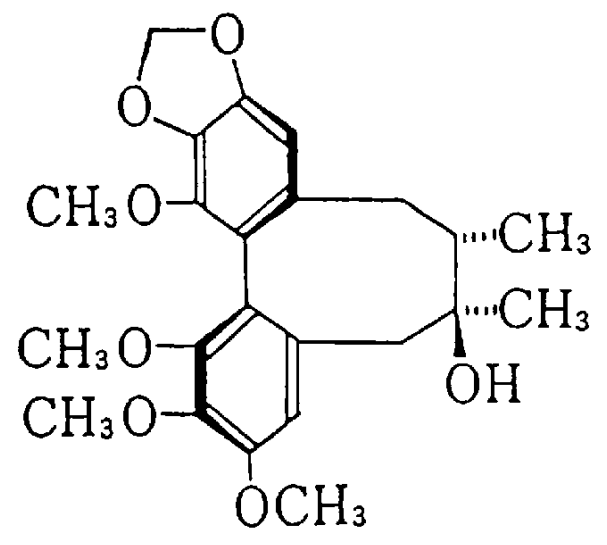

Fig. 1. Structure of Gomisin A.

was obtained from Japan Clea Co., Tokyo. Diets containing $0.01 \%$ and $0.03 \%$ gomisin $\mathrm{A}$ and $0.06 \% 33^{\prime}$-MeDAB were prepared at Nihon Haigoushiryo Co., Aichi. Phenobarbital (Hoei Yakukoh Co.) was dissolved in water at a concentration of $0.05 \%$.

\section{Rats and feeding protocol}

Male Donryu rats (6-weeks-old, Japan Clea) were divided into 8 groups, and 5 rats were housed in a cage. Animals were fed and given water containing drugs ad libitum according to the following protocol (11) (Table 1) and killed for histopathological study at $0,5,10$, 20, and 40 weeks after starting the feeding gomisin A and phenobarbital.

\section{Histopathological observation}

The liver was excised and fixed in $10 \%$ phosphate-buffered formalin solution. Three sections, obtained from the right anterior, left anterior, and left median lobes, were stained with hematoxylin and eosin (H.E.). The number, areas and size of hepatic altered foci were measured in H.E.-stained sections using an image processor (Digitizer GT-4100, Photoron Co., Ltd.) with an Image Measuring System (Finetec Co., Ltd.).

Statistical analyses were done by Student's $t$-test and the Welch test.

\section{RESULTS}

During the experiments, gomisin A, even at a high dosage $(0.03 \%$ of the diet), hardly influenced the diet and water consumption and the body and liver weights of rats pretreated or not pretreated with 3'-MeDAB. Phenobarbital suppressed the increase of body weight and water consumption, perhaps due to its bitter taste, but increased the liver weight, so the ratio of liver weight vs. body weight of rats given phenobarbital was significantly higher than that of the control and gomisin A groups (Table 2 and Fig. 2). No behavioral change was apparent in rats fed gomisin A or phenobarbital.

Table 1. Feeding protocol of $0.06 \%$ 3'-MeDAB-containing diet (3'-MeDAB) and gomisin A or phenobarbital (PB)

\begin{tabular}{|c|c|c|c|}
\hline \multirow[t]{2}{*}{ Group } & \multicolumn{3}{|c|}{ Fecding period } \\
\hline & 3 weeks & 2 weeks & 40) weeks \\
\hline 1 & Basal diet & Basal diet & Basal diet \\
\hline 2 & Basal dict & Basal dict & $0.03 \%$ Gomisin A-containing diet \\
\hline 3 & Basal diet & Basal diet & $0.01 \%$ Gomisin A-containing dict \\
\hline 4 & Basal diet & Basal diet & $0.05 \%$ PB-containing water \\
\hline 5 & 3'-MeDAB & Basal diet & Basal diet \\
\hline 6 & 3'-MeDAB & Basal diet & $0.03 \%$ Gromisin A-containing diet \\
\hline 7 & 3'-MeDAB & Basal diet & $0.01 \%$ Gomisin A-containing diet \\
\hline 8 & 3'-MeDAB & Basal diet & $0.05 \%$ PB-containing water \\
\hline
\end{tabular}


Table 2. Body and liver weight and relative liver weight of rats after feeding gomisin A (G) or phenobarbital (PB) for 40 weeks

\begin{tabular}{|c|c|c|c|c|}
\hline Group & Treatment & $\begin{array}{l}\text { Body weight } \\
\text { (g) }\end{array}$ & $\begin{array}{l}\text { Liver weight } \\
\text { (g) }\end{array}$ & $\begin{array}{c}\text { Liver/body } \\
(\%)\end{array}$ \\
\hline 1 & Basal-Basal & $585.3 \pm 46.7$ & $19.6 \pm 1.8$ & $3.3 \pm 0.2$ \\
\hline 2 & Basal-0.03\% G & $586.2 \pm 57.0$ & $20.5 \pm 2.2$ & $3.5 \pm 0.2$ \\
\hline 3 & Basal-0.01\% G & $586.8 \pm 51.7$ & $20.0 \pm 1.9$ & $3.4 \pm 0.4$ \\
\hline 4 & Basal-0.05\% PB & $570.0 \pm 32.5$ & $24.9 \pm 2.1^{*}$ & $4.4 \pm 0.2^{*}$ \\
\hline 5 & 3'-MeDAB - Basal & $591.0 \pm 71.2$ & $20.2 \pm 2.9$ & $3.5 \pm 0.6$ \\
\hline 6 & 3'-MeDAB $-0.03 \% \mathrm{G}$ & $585.3 \pm 36.1$ & $21.8 \pm 2.3$ & $3.7 \pm 0.3$ \\
\hline 7 & $3^{\circ}-\mathrm{MeDAB}-0.01 \% \mathrm{G}$ & $594.8 \pm 66.3$ & $22.7 \pm 3.3$ & $3.8 \pm 0.5$ \\
\hline 8 & 3'-MeDAB $-0.05 \%$ PB & $550.0 \pm 49.3$ & $27.7 \pm 3.6^{* *}$ & $5.1 \pm 0.8^{* *}$ \\
\hline
\end{tabular}

Valucs are the mcan \pm S.D. ${ }^{*}{ }^{* *}$ Significant difference with $\mathrm{P}<0.01$ from groups 1 and 5 , respectively.

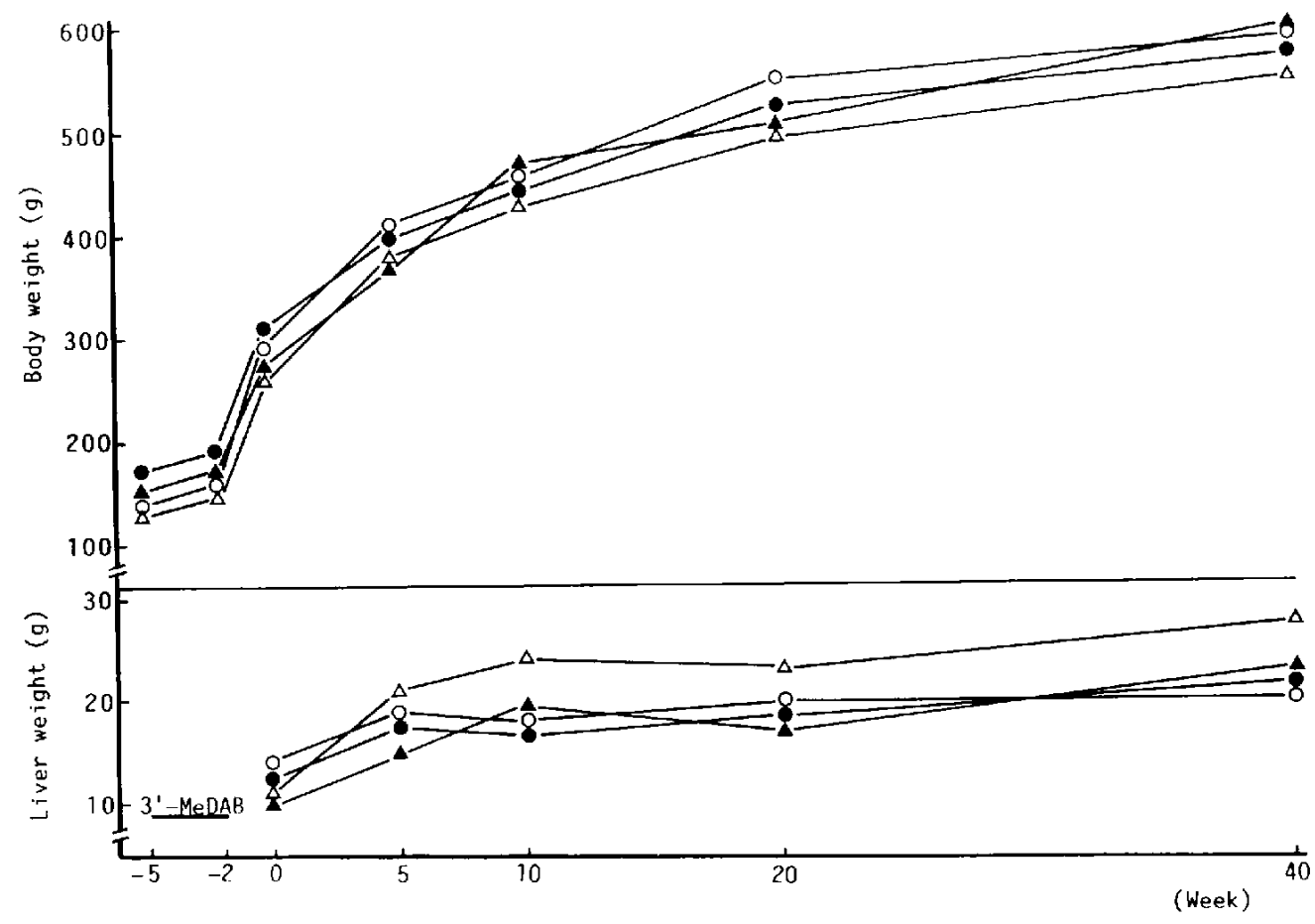

Fig. 2. Body and liver weight changes in rats during feeding of 3'-MeDAB and gomisin $A$ or phenobarbital Upper: body weight. Lower: liver weight. $0.06 \%$ 3'-MeDAB-containing diet alone, $\mathbf{A}$ : combined with $0.01 \%$ gomisin A-containing diet, $\mathrm{O}$ combined with $0.03 \%$ gomisin A-containing diet, $\triangle$ : combined with $0.05 \%$ phenobarbital-containing water. 
In rats fed gomisin $\mathrm{A}$ or phenobarbital alone, no neoplastic change was histopathologically observed until 40 weeks. The number of histopathological lesions observed in the liver preparations from 3'-MeDAB-pretreated rats is shown in Table 3. Hepatic altered foci were observed in almost all the rats fed the 3'McDAB-containing diet. The total number of altered foci in the 3'-MeDAB-control group rapidly increased, reached a peak at 10 weeks (12 weeks after the stopping the 3'-MeDAB diet), and thereafter decreased and maintained a level of 4 to 6 foci $/ \mathrm{cm}^{2} /$ rat (Fig. 3). Gomisin A inhibited the appearance of the altered foci in the early period of the fecding: at a high dosage of gomisin A $(0.03 \%)$, small foci (below $700 \mu \mathrm{m}$ diameter) were clearly fewer than in the control group during the experiment and large foci (over $701 \mu \mathrm{m}$ diameter) were very few; and at a low dosage of gomisin A $(0.01 \%)$, the number of altered foci was less than in the control group until 10 weeks and then gradually increased. In the phenobarbital-combined group, the number of large foci (over $701 \mu \mathrm{m}$ diameter) was significantly higher than that in the control group during the experiment and a certain number of hyperplastic nodules and hepatomas was also observed.

As shown in Table 4, we classified the foci of hepatocellular alterations as previously indicated (13). Most commonly observed hyperplastic foci in the 3'-MeDAB-treated groups were of the clear cell type, and gomisin A decreased the number of such types of foci in the early stage. A high incidence of basophilic cell foci was temporarily observed at 5 weeks in the control and $0.01 \%$ gomisin $\mathrm{A}$ groups. In

Table 3. Histopathological lesions in the liver during feeding of gomisin A (G) or phenobarbital (PB) after treatment with 3'-MeDAB

\begin{tabular}{|c|c|c|c|c|c|c|}
\hline \multirow{3}{*}{\multicolumn{2}{|c|}{ Group }} & \multirow[t]{3}{*}{$\begin{array}{l}\text { Period } \\
\text { of feeding } \\
\text { (week) }\end{array}$} & \multirow[t]{3}{*}{$\begin{array}{l}\text { No. of rats with lesions } \\
\text { No. of rats examined }\end{array}$} & \multicolumn{2}{|c|}{$\begin{array}{l}\text { Number of foci with the } \\
\text { following diameters } \\
\left.\text { (No. } / \mathrm{cm}^{2} / \mathrm{rat}\right)\end{array}$} & \\
\hline & & & & below & over & \\
\hline & & & & $700 \mu \mathrm{m}$ & $701 \mu \mathrm{m}$ & \\
\hline \multirow[t]{5}{*}{5} & Basal diet & 0 & $10 / 10$ & $5.89 \pm 3.61$ & $0.02 \pm 0.04$ & $(0)$ \\
\hline & & 5 & $9 / 10$ & $6.35 \pm 3.92$ & $0.48 \pm 0.69$ & (0) \\
\hline & & 10 & $10 / 10$ & $7.24 \pm 3.68$ & $0.37 \pm 0.36$ & $(0)$ \\
\hline & & 20 & $9 / 10$ & $3.39 \pm 2.20$ & $0.30 \pm 0.43$ & $(0.09 \pm 0.20)$ \\
\hline & & 40 & $10 / 10$ & $5.47 \pm 3.43$ & $0.34 \pm 0.59$ & (0) \\
\hline \multirow[t]{4}{*}{6} & $0.03 \% \mathrm{G}$ & 5 & $10 / 10$ & $3.44 \pm 2.54$ & $0.05 \pm 0.14$ & $(0)$ \\
\hline & & 10 & $10 / 10$ & $3.09 \pm 1.89^{* 2}$ & $0.11 \pm 0.24$ & $(0)$ \\
\hline & & 20 & $10 / 10$ & $3.09 \pm 1.85$ & $0.31 \pm 0.69$ & (0) \\
\hline & & 40 & $9 / 10$ & $3.84 \pm 2.44$ & $0.35 \pm 0.33$ & $(0.05 \pm 0.15)$ \\
\hline \multirow[t]{4}{*}{7} & $0.01 \% \mathrm{G}$ & 5 & $9 / 10$ & $3.06 \pm 2.13^{* 1}$ & $0.34 \pm 0.39$ & $(0)$ \\
\hline & & 10 & $10 / 10$ & $4.71 \pm 2.71$ & $0.17 \pm 0.28$ & (0) \\
\hline & & 20 & $10 / 10$ & $5.27 \pm 3.33$ & $0.39 \pm 0.32$ & (0) \\
\hline & & 40 & $10 / 10$ & $5.69 \pm 4.11$ & $0.64 \pm 0.83$ & $(0.18 \pm 0.31)$ \\
\hline \multirow[t]{4}{*}{8} & $0.05 \% \mathrm{~PB}$ & 5 & $10 / 10$ & $5.21 \pm 3.15$ & $1.46 \pm 1.09^{* 1}$ & $(0.09 \pm 0.19)$ \\
\hline & & 10 & $10 / 10$ & $10.56 \pm 6.43$ & $1.18+1.32$ & $(0.11 \pm 0.34)$ \\
\hline & & 20 & $10 / 10$ & $4.77 \pm 2.93$ & $1.63 \pm 1.25^{* 2}$ & $\left(0.64 \pm 0.66^{* 1}\right)$ \\
\hline & & 40 & $10 / 10$ & $5.56 \pm 2.58$ & $1.29 \pm 1.10^{* 1}$ & $(0.71 \pm 0.62)$ \\
\hline
\end{tabular}

Data are the mean \pm S.D. Data in paretheses indicate the number of hyperplastic nodules and hepatomas. $* 1, * 2$ significant difference from the corresponding period of group 5 , with $\mathrm{P}<0.05$ and $\mathrm{P}<0.01$. 


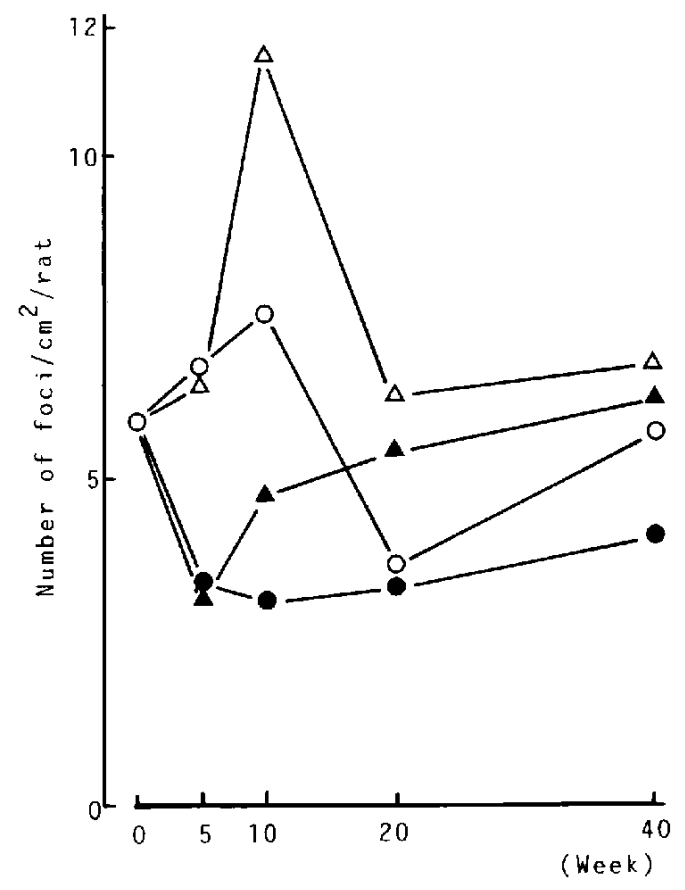

Fig. 3. Change in number of altered foci in the liver. Data indicate the mean of the number of foci during feeding of the basal diet $(\bigcirc), 0.01 \%$ gomisin A-containing diet (A), $0.03 \%$ gomisin A-containing diet (O) and $0.05 \%$ phenobarbital-containing water $(\Delta)$ after treatment with $0.06 \% 3$ '-MeDAB for 3 weeks and suspension for 2 weeks.

the $0.03 \%$ gomisin A group, basophilic cell foci were few for 20 weeks and increased only at 40 weeks. The other types were very few in the control and gomisin A groups. Phenobarbital increased every type of neoplastic lesion, and a particular change was a very high incidence of eosinophilic cell foci.

\section{DISCUSSION}

The two-step theory has been proposed for carcinogenesis by physical, chemical, and viral carcinogens (14). Phenobarbital enhanced the hepatic tumor incidence when it was fed to rats after their exposure to a carcinogen, whilc the simultaneous feeding of phenobarbital and carcinogen reduced carcinogenesis (9). Thus, phenobarbital acts as a promoter of progress in initiated cells. Kitagawa and Sugano (11) have reported that subsequent feeding of 3 MeDAB (3 weeks) and phenobarbital (36 weeks) caused a considerable number of neoplastic changes in the livers of rats.

It has been reported that gomisin $\mathrm{A}$ accelerates the liver regeneration and increases the cell division after a partial hepatectomy $(7,8)$ as mentioned for phenobarbital (15). In this study, we then examined the effects of gomi$\sin \mathrm{A}$ on the tumor progression in the liver after a short-term feeding of 3'-MeDAB to rats, in comparison to the effects of phenobarbital. In groups fed gomisin A or phenobarbital alone, no hepatic alteration was observed during this experiment. Altered foci in the liver increased after the feeding of 3'-MeDAB and reached a peak 12 weeks after treatment with the carcinogen. Phenobarbital enhanced the alterations so that the number and size of the foci were much larger in the phenobarbital group than in the control group. In contrast, gomisin A decreased the number in early stages. In the morphological classification and typing of hepatocellular alterations, the clear cell type of alteration accounted for most of the foci, and basophilic cell foci appeared with a high incidence in the early stage after 3'MeDAB feeding. The numbers of clear cell and basophilic cell foci were decreased by subsequent feeding of gomisin $A$. In the phenobarbital-combined group, a large number of the eosinophilic ccll type and a gradual increase of the mixed cell type were characteristic changes. Thesc results suggest that gomi$\sin A$ inhibits or delays the promotion step of cells initiated by a carcinogen, while phenobarbital strongly promotes hepatocarcinogenesis.

Gomisin A, like phenobarbital, enhances hepatic regeneration and increases the mitotic index after a partial hepatectomy $(7,8,15)$, but the former suppressed and the latter promoted hepatocarcinogenesis. It may be concluded that the effects of gomisin A on the liver after hepatectomy are events different from the carcinogenic actions. Ito et al. (16, 17) indicated that some hyperplasia increased in the early period after feeding of carcinogens 
Table 4. Number of altered foci found in the liver during feeding gomisin $A$ or phenobarbital after treatment with 3 -MeDAB

\begin{tabular}{|c|c|c|c|c|c|c|c|c|}
\hline \multirow{2}{*}{\multicolumn{2}{|c|}{ Group }} & \multirow{2}{*}{$\begin{array}{c}\text { Period } \\
\text { of feeding } \\
\text { (week) }\end{array}$} & \multicolumn{6}{|c|}{$\begin{array}{c}\text { Type of foci } \\
\text { (Number } / \mathrm{cm}^{2} / \mathrm{rat} \text { ) }\end{array}$} \\
\hline & & & Clr. & & Vac. & Eos. & Bas. & Mix. \\
\hline \multirow[t]{4}{*}{5} & Basal diet & 5 & $4.07 \pm 2.97$ & 0.39 & \pm 0.38 & $0.14 \pm 0.22$ & $2.13 \pm 1.58$ & $0.10 \pm 0.21$ \\
\hline & & 10 & $6.66 \pm 3.48$ & 0.13 & \pm 0.42 & $0.13 \pm 0.42$ & $0.54 \pm 0.63$ & $0.14 \pm 0.31$ \\
\hline & & 20 & $2.93 \pm 1.81$ & 0.25 & +0.63 & $0.04 \pm 0.12$ & $0.39 \pm 0.51$ & $0.08+0.18$ \\
\hline & & 40 & 4.78 上 3.12 & 0.37 & \pm 0.65 & $0.39 \pm 0.73$ & $0.27 \pm 0.29$ & 0 \\
\hline \multirow[t]{4}{*}{6} & $0.03 \% \mathrm{G}$ & 5 & $2.84 \pm 2.47$ & 0.09 & \pm 0.29 & $0.11 \pm 0.23$ & $0.40 \pm 0.37^{* 2}$ & $0.05 \pm 0.16$ \\
\hline & & 10 & $2.28 \pm 1.52^{* 3}$ & 0.05 & \pm 0.17 & $0.10 \pm 0.21$ & $0.50 \pm 0.72$ & $0.28 \pm 0.41$ \\
\hline & & 20 & $2.89 \pm 1.92$ & 0.09 & \pm 0.18 & $0.06 \pm 0.17$ & $0.37 \pm 0.50$ & 0 \\
\hline & & 40 & $2.90 \pm 2.18$ & 0.15 & \pm 0.31 & $0.10 \pm 0.19$ & $0.97 \pm 0.90$ & $0.08 \pm 0.17$ \\
\hline \multirow[t]{4}{*}{7} & $0.01 \% \mathrm{G}$ & 5 & $1.02 \pm 0.69^{* 1}$ & 0.30 & \pm 0.42 & $0.24 \pm 0.43$ & $1.72 \pm 1.25$ & $0.12 \pm 0.25$ \\
\hline & & 10 & $4.30 \pm 2.60$ & 0.06 & \pm 0.19 & $0.12 \pm 0.26$ & $0.29 \pm 0.49$ & $0.11 \pm 0.24$ \\
\hline & & 20 & $5.06 \pm 3.11$ & 0.22 & \pm 0.31 & 0 & $0.37 \pm 0.58$ & 0 \\
\hline & & 40 & $4.93 \pm 3.98$ & 0.24 & \pm 0.25 & $0.48 \pm 0.51$ & $0.64 \pm 0.75$ & $0.05 \pm 0.15$ \\
\hline \multirow[t]{4}{*}{8} & $0.05 \% \mathrm{~PB}$ & 5 & $2.13 \pm 3.47$ & 0.09 & $\pm 0.19^{* 1}$ & $3.04 \pm 1.49^{* 4}$ & $1.04 \pm 0.84$ & $0.37+0.35$ \\
\hline & & 10 & $8.39 \pm 7.05$ & 0.13 & \pm 0.21 & $2.20 \pm 1.66^{* 3}$ & $0.65 \pm 1.03$ & $0.37 \pm 0.33$ \\
\hline & & 20 & $2.03 \pm 1.88$ & 0.48 & \pm 0.61 & $2.29 \pm 2.08^{* 2}$ & $0.79 \pm 0.78$ & $0.81 \pm 0.74^{* 1}$ \\
\hline & & 40 & 3.14 上 2.02 & 0.34 & \pm 0.36 & $1.81+0.88^{* 4}$ & $0.65 \pm 0.79$ & $0.92 \pm 0.90$ \\
\hline
\end{tabular}

Data are the mean \pm S.D. Abbreviations: G, gomisin A; PB, phenobarbital; Clr., clear cell type; Vac., Vacuolar cell type; Eos., eosinophilic cell type; Bas., basophilic cell type; Mix., mixed cell type. ${ }^{* 1}, *^{2},{ }^{* 3},{ }^{* 4}$ Significant difference from the corresponding period of group 5 , with $\mathrm{P}<0.05, \mathrm{P}<0.01, \mathrm{P}<0.005$, and $\mathrm{P}<0.001$, repectively.

contain reversible lesions and a few of the lcsions are then committed to neoplastic transformation. Gomisin A suppressed the appearance of the lesions in the carly stages after 3'-MeDAB. It is possible that gomisin A decreases the reversible fractions by improving of hepatic functions $(6-8)$. Other molecular mechanisms of inhibition by gomisin $\mathrm{A}$ of tumor promotion should be considered and investigations on these mechanisms are in progress in our laboratory.

\section{Acknowledgment}

Wc thank K. Sasahara of Tsumura Research Institute for Pharmacology for his kind cooperation during this project.

\section{REFERENCES}

1 Ikeya, Y., Taguchi, H., Yoshioka, I. and Kobayashi, H.: The constituents of Schizandra chinensis Baill. I. Isolation and structure determination of five lignans, gomisin A, B, C, F and $G$, and the absolute structure of schizandrin. Chem. Pharm. Bull. (Tokyo) 27, 1383-1394 (1979)

2 Macda, S., Sudo, K., Miyamoto, Y., Takeda, S., Shinbo, M., Aburada, M., Ikeyd, Y., Taguchi, H. and Harada, M.: Pharmacological studies on schizandra fruits. I1. Effects of constituents of schizandra fruits on drug induced hepatic damage in rats. Yakugaku Zasshi 102, 579-588 (1982) (Abs. in English)

3 Takeda, S., Maemura. S., Sudo, K., Kase, Y., Arai, I., Ohkura, Y., Funo, S., Fujii, Y.. Aburada, M. and Hosoya, E.: Effects of gomisin A, a lignan component of Schizandra fruits, on experimental liver injuries and liver microsomal 
drug-metabolizing enzymes. Folia Pharmacol. Japon. 87, 169-187 (1986) (Abs. in English)

4 Hikino, H., Kiso, Y., Taguchi, H. and Ikeya, Y.: Antihepatotoxic actions of lignoids from Schizandra chinensis fruits. Planta Med. 50, 213-218 (1984)

5 Kiso, Y., Tohkin, M., Hikino, H., Ikeya, Y. and Taguchi, H.: Mechanism of antihepatotoxic activity of Wuweizisu $C$ and Gomisin A. Planta Med. 51, $331-334$ (1985)

6 Maeda, S., Takeda, S., Miyamoto, Y., Aburada, M. and Harada, M.: Effect of gomisin A on liver functions in hepatotoxic chemicals-treated rats. Japan. J. Pharmacol. 38, $347-353$ (1985)

7 Takeda, S., Kase, Y., Arai, I., Hasegawa, M. Sekiguchi, Y., Funo, S., Aburada, M., Hosoya, E., Mizoguchi, Y. and Morisawa, S.: Effects of TJN-101 ((+)-(6s,7s,R-biar)-5,6,7,8-tetrahydro1,2,3,12-tetramethoxy-6,7-dimethyl-10,11-methylenedioxy-6-dibenzo[a,c]cyclooctenol) on liver regeneration after partial hepatectomy, and on regional hepatic blood flow and fine structure of the liver in normal rats. Folia Pharmacol. Japon. 88 , 321 - 330 (1986) (Abs. in English)

8 Takeda, S., Kase, Y., Arai, I., Ohkura, Y.. Hasegawa, M., Sekiguchi, Y., Tatsugi, A., Funo, S., Aburada, M. and Hosoya, E.: Effects of TJN. 101, a lignan compound isolated from Schizandra fruits, on liver fibrosis and on liver regeneration after partial hepatectomy in rats with chronic liver injury induced by $\mathrm{CCl}_{4}$. Folia Pharmacol. Japon. 90, 51-65 (1987) (Abs. in English)

9 Peraino, C., Fry, R.J.M. and Staffeldt, E.: Reduction and enhancement by phenobarbital of hepatocarcinogenesis induced in the rat by 2-acetylaminofluorene. Cancer Res. 31, 1506-1512 (1971)
10 Kitagawa, T. and Sugano, H.: Enhancement of azo-dye hepatocarcinogenesis with dietary phenobarbital in rats. Japan. J. Cancer Res. (Gann) 68 , $255-256$ (1977)

11 Kitagawa, T. and Sugano, H.: Enhancing effect of phenobarbital on the development of cnzymcaltered islands and hepatocellular carcinomas initiated by 3'-methyl-4-(dimethylamino)azabenzene or dicthylnitrosamine. Japan. J. Cancer Res. (Gann) 69, $679-687$ (1978)

12 Gicse, J.E., Clayton, C.C., Miller, E.C. and Baumann, C.A.: The effect of certain diets on hepatic tumor formation due to $m$ '-methylp-dimethylaminoazobenzcne and $o^{\prime}$-methyl-pdimethylaminoazobenzene. Cancer Res. 6, 678684 (1946)

13 Squire, R.A. and Levitt, M.H.: Report of a workshop on classification of specific hepatocellular lesions in rats. Cancer Res. 35, 3214-3223 (1975)

14 Farber, E.: The sequential analysis of liver cancer induction. Biochim. Biophys. Acta 605, 149-166 (1980)

15 Japundzic, M., Knezevic, B., Djordjevic-Camba, $V$. and Japundzic, I.: The influence of phenobarbital-Na on the mitotic activity of parenchymal liver cells during rat liver regeneration. Exp. Cell Res. 48, 163-167 (1967)

16 Ito, N., Hananouchi, Sugihara, S., Shirai, T., Tsuda, H., Fukushima, $S$. and Nagasaki, H.: Reversibility and irreversibility of liver tumors in mice induced by the $\alpha$ isomer of $1,2,3,4,5,6$ hexachlorocyclohexane. Cancer Res. 36, $2227-$ 2234 (1976)

17 Ito, N.: Development of carcinomas and pre-neoplastic changes in rat liver. Gan to Kagakuryoho 7, Supp. I, 55-63 (1980) (Abs. in English) 